Kriss et al. (1964) postulated that the destruction of the thyroid gland by disease (hyperthyroidism or thyroiditis) or by therapeutic agents (especially ${ }^{131} \mathrm{I}$ ) results in the release of an antigen of thyroid cell origin which then stimulates the production of the antibody, LATS. The antibody is then fixed to the tissues of the legs, the phenomenon being facilitated by a number of factors such as dependency of the lower limbs, trauma, vascular injury, cardiac failure, exposure to cold or hypothyroidism. The resulting immunological reaction then causes a local inflammatory tissue reaction which manifests as pretibial myxoedema. It is therefore interesting to note that two of our patients had elevated levels of IgG. Although the levels of LATS were not determined in these patients, the high level of IgG would support an immunological mechanism underlying the pathogenesis of pretibial myxoedema. In this context, it is significant that pretibial myxoedema has also been found in patients with Hashimoto's thyroiditis (Peard, 1961) and myxoedema with lymphocytic infiltration of the thyroid gland (Haydar, 1963). There may therefore be a common factor which induces inflammatory changes in the thyroid gland as well as causing exophthalmos, pretibial myxoedema and clubbing.

\section{References}

BeIghton, P. (1968) LATS activity, exophthalmos and digital clubbing associated with myxoedema. Postgraduate Medical Journal, 44, 426.
CheW, B.K., YU, M. \& WeE, R. (1969) Immunoglobulin levels in four ethnic groups in Singapore. Far East Medical Journal, 5, 98.

Gimlette, T.M.D. (1960) Pretibial myxoedema. British Medical Journal, ii, 348.

GreER, M.A. (1957) Exophthalmos and localised pretibial myxoedema in a euthyroid patient. Journal of Clinical Endocrinology and Metabolism, 17, 1466.

Gorman, C.A. (1972) Unusual manifestations of Graves' Disease. Mayo Clinic Proceedings, 47, 926.

HAYDAR, N.A. (1963) Exophthalmos, digital clubbing and pretibial myxoedema in thyroiditis. Journal of Clinical Endocrinology and Metabolism, 23, 215.

Kriss, J.P., Pleshakor, V. \& Chein, J.R. (1964) Isolation and identification of the long acting thyroid stimulator and its relation of hyperthyroidism and circumscribed pretibial myxoedema. Journal of Clinical Endocrinology and Metabolism, 24, 1005.

LeVer, W.F. (1961) Histopathology of the Skin, 3rd edn, p. 353. J. B. Lippincott Co., Philadelphia and Montreal.

Peard, M.C. (1961) Lymphadenoid goitre with hypothyroidism, exophthalmos, pretibial myxoedema and acropachy. Proceedings of the Royal Society of Medicine, 54, 342.

Shasky, D. \& Nelson, J. (1966) Pretibial myxoedema. Archives of Dermatology, 94, 658.

Warthins, T.A. \& Boshell, B.R. (1957) Pretibial myxoedema. American Medical Association Archives of Internal Medicine, 100, 319.

Werner, S.C. (1969) Classification of the eye changes of Graves' disease. Journal of Clinical Endocrinology and Metabolism, 29, 982.

\title{
Autoimmune haemolytic anaemia and ulcerative colitis
}

\author{
D. W. Gorst \\ M.A., B.M., B.Ch., M.R.C.P. \\ M. J. LEYLAND
M.R.C.P. \\ I. W. Delamore \\ Ph.D., F.R.C.P.Ed., M.C.Path. \\ University Department of Clinical Haematology, Royal Infirmary, Manchester
}

\begin{abstract}
Summary
Two cases of ulcerative colitis are described in which there was associated severe auto-immune haemolytic anaemia. The colitis in both patients responded to conventional therapy and one patient underwent splenectomy for her anaemia. Possible aetiological links are discussed.
\end{abstract}

ANAEMIA is a common accompaniment of ulcerative colitis. It is usually due to gastro-intestinal blood loss or to marrow depression with impaired release of reticulo-endothelial iron associated with chronic inflammation.

The association of ulcerative colitis and autoimmune haemolytic anaemia has been described, but 
it is relatively rare and there are only four cases reported in the literature (Dacie, 1962; Edwards and Truelove, 1964; Lorber, Schwartz and Wassermann, 1955). Since there is possibly an important immunological link between these conditions, two further cases are reported.

\section{Case 1}

A 30-year-old Caucasian housewife was referred with a 3-year history of a Coombs-positive autoimmune haemolytic anaemia. Serology showed her to be group $A$ Rh-negative ( $\overline{c d e} / \bar{c} d \bar{e})$. An Rh-like complex acting by Coombs in albumin and papain only was detected in the serum and in the red cell eluate which was removed after separate absorption with group $\mathrm{O} R_{1} R_{1}, R_{2} R_{2}$ and $r r$ red cells. ANF, Australia antigen and antibody and rheumatoid factor were not present in the serum. Initial response to prednisolone was good and she was maintained on small doses of steroids during her third pregnancy. She relapsed in the puerperium and despite $50 \mathrm{mg} /$ day of prednisolone, the haemoglobin fell to $7 \cdot 8 \mathrm{~g} \%$ with $80 \%$ reticulocytes and a bilirubin of $8 \mathrm{mg} \%$. The spleen was palpable, the red cell half-life ${ }^{51} \mathrm{Cr}$ was $2 \cdot 5$ days and the corrected spleen/liver ratio of the surface counts was $1 \cdot 42$. Splenectomy was performed and 6 weeks later the haemoglobin had risen to $14.5 \mathrm{~g} \%$ with a normal reticulocyte count, and the steroids were gradually withdrawn. Four months later the haemoglobin was $14.6 \mathrm{~g} \%$ with $4.2 \%$ reticulocytes, but during this period the patient developed colitis. She had frequent bowel actions (up to eight daily) passing mucus and blood with considerable tenesmus. Direct questioning revealed that similar albeit milder symptoms were present in the 12 months before the anaemia, but there were no bowel symptoms during the period on steroid treatment. Sigmoidoscopy revealed a red, velvety, friable mucosa and biopsy showed typical histological features of ulcerative colitis. Barium enema showed the disease to extend proximally to the mid descending colon. Immunofluorescence studies of the rectal biopsy revealed no accumulation of immunoglobulin or immune complexes. Serum levels of immunoglobulins were IgG $1220 \mathrm{mg} \%, \operatorname{IgA} 290$ $\mathrm{mg} \%$, IgM $150 \mathrm{mg} \%$.

\section{Case 2}

A 36-year-old Caucasian female presented with an episode of rectal bleeding, her second, after which she became anaemic and deeply jaundiced. Her blood count at that time was: WBCs, $8600 / \mathrm{mm}^{3}$;

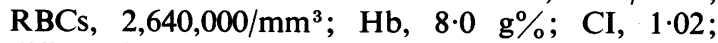
differential, normal; platelets, $387,000 / \mathrm{mm}^{3}$; reticulocytes, $11 \cdot 5 \%$.

The spleen was palpable, she had a strongly positive direct Coombs' test (anti- $\gamma$ ) and an abnormal antibody thought to be an anti-C or anti-è was de- tected in the serum. Serum folate was reduced at $1.85 \mathrm{mg} / \mathrm{ml}$ and the bone marrow showed marked normoblastic hyperplasia. Red blood cell fragility was increased. Sigmoidoscopy to $20 \mathrm{~cm}$ was performed and the mucosa was seen to be granular, and showed contact bleeding. There was pus in the bowel lumen. Multiple biopsies were taken, and showed acute pyogenic inflammation with crypt abscesses. No ulcers were seen but the surface epithelium was regenerative and the appearance was considered to be that of ulcerative colitis.

Her colitis was treated with prednisolone retention enemata, but the haemolytic process required a combination of large doses of systemic steroids and 6-mercaptopurine to maintain the haemoglobin between 8 and $11 \mathrm{~g} \%$. After a period of 5 years, improvement occurred and eventually all treatment was stopped. She has been reassessed recently and found to be well, with a haemoglobin of $14.0 \mathrm{~g} \%$, reticulocytes $1.3 \%$, ESR $4 \mathrm{~mm}$ in first hour. The direct Coombs' test was positive (anti- $\gamma$ ), but only a very weak antibody was detected by the albumin technique. Repeat sigmoidoscopy showed slight hyperaemia and contact bleeding of the mucosa, and biopsy confirmed the quiescence of the disease. Immunofluorescence studies of the biopsy did not reveal deposition of $\gamma$-globulin or immune complexes and no other auto-antibodies were demonstrable in the serum.

\section{Comments}

The association of two uncommon diseases is always of interest and Dacie (1962), in his monograph, mentions two cases of auto-immune haemolytic anaemia associated with ulcerative colitis in a series of 234 cases of auto-immune haemolytic anaemia, both warm and cold antibody: both cases reported here were of the warm antibody type. Four cases of ulcerative colitis were reported by Lorber $e t$ al. (1955) in which a positive direct Coombs' test was found, but only in one was there evidence of significant haemolysis. Edwards and Truelove (1964) mention a single patient in their review, but no details are given. The two patients in this report have severe auto-immune haemolytic anaemia in conjunction with ulcerative colitis.

The pathogenesis of ulcerative colitis is unknown, but there is evidence that it has an auto-immune basis in some cases. Apart from the association with other conditions thought to have an auto-immune aetiology it has been shown that about $10 \%$ of ulcerative colitic patients have in their serum antibodies capable of reacting with fetal colon (Broberger and Perlmann, 1959).

Auto-immune haemolytic anaemia is well recognized as a prime example of auto-immune disease and organ-specific antibodies are easily demonstrable. 
The exact relationship between ulcerative colitis and auto-immune haemolytic anaemia in these two cases is not known and it is possible that it is fortuitous. However, since there is evidence that both diseases have an immunological basis, it would seem likely that the cause of the two conditions is in some way linked. In any event, it is important to consider haemolysis as a cause of anaemia in ulcerative colitis.

\section{References}

Broberger, O. \& Perlmann, P. (1959) Autoantibodies in human ulcerative colitis. Journal of Experimental Medicine, $110,657$.

Davie, J.V. (1962) The Haemolytic Anaemias II, p. 343. J. A. Churchill Ltd, London.

Edwards, F.C. \& Truelove, J.C. (1964) The course and prognosis of ulcerative colitis. III. Complications. Gut, $\mathbf{5}, 1$.

Lorber, M., Schwartz, L.I. \& Wasserman, L.R. (1955) Association of antibody-coated red blood cells with ulcerative colitis. American Journal of Medicine, 19, 887.

Postgraduate Medical Journal (June 1975) 51, 411-412.

\title{
Gastric carcinoma and Turner's syndrome
}

\author{
D. SIEGLER \\ M.B., M.R.C.P. \\ Royal Free Hospital, London NW3
}

\begin{abstract}
Summary
The case is described of a gastric carcinoma developing in a 34-year-old female with Turner's syndrome. The association has not been previously reported. The literature on the appearance of malignant disease in disorders of the sex chromosomes is reviewed.
\end{abstract}

\section{History}

An unmarried 34-year-old female was first seen in February 1973, with a 3-week history of dull epigastric pain relieved by food, vomiting but no haematemesis, weakness, effort dyspnoea and thirst and polyuria. She had never had a menstrual period. On examination she was obviously anaemic and had many external stigmata of Turner's syndrome, including short stature $(148.6 \mathrm{~cm})$, scanty pubic and axillary hair, numerous pigmented naevi, undeveloped breasts, a low hair-line at the back of the neck, and was mentally subnormal. There was a soft apical pansystolic murmur. Routine urine testing revealed $2 \%$ glycosuria.

\section{Investigations}

Haemoglobulin $6.7 \mathrm{~g} / 100 \mathrm{ml}$; MCHC 28; WBC $7000 / \mathrm{mm}^{3}$; platelet count normal; serum and red cell folate, serum B12, urea and electrolytes, liver function tests, protein-bound iodine, total proteins and electrophoretic strip and chest $X$-ray were all normal; a buccal smear showed the typical chromosome count of Turner's syndrome (45XO).

Barium meal and swallow were normal; an IVP revealed bilateral duplex pelvi-calyceal and ureteric systems; a skeletal survey was normal except for unfused iliac epiphyses and spina bifida occulta of S1 and S2; gastroscopy and sigmoidoscopy were nor- mal; a glucose tolerance curve was of diabetic type; serum iron was reduced to $55 \mu \mathrm{g} / 100 \mathrm{ml}$ with a TIBC of $480 \mu \mathrm{g} / 100 \mathrm{ml}$.

A diagnosis of iron deficiency anaemia of undetermined aetiology was made.

\section{Treatment}

She was treated with oral ferrous sulphate with a resultant $20 \%$ reticulocytosis and a return of haemoglobin concentration to normal. Her diabetes mellitus was controlled on oral tolbutamide.

\section{Progress}

She remained well until July 1973 when she was re-admitted to hospital because her haemoglobulin had fallen to $4.9 \mathrm{~g} / 100 \mathrm{ml}$. She received blood transfusion and oral ferrous sulphate and remained well until November 1973 when she was re-admitted with vomiting and anaemia of $7 \cdot 2 \mathrm{~g} / 100 \mathrm{ml}$. At gastroscopy (Mr R. M. Kirk) a rigid non-peristaltic mass was seen in the pre-pyloric region and at laparotomy, a pyloric carcinoma with extensive hepatic and peritoneal metastases was found. Gastro-jejunostomy was performed. Histology revealed an undifferentiated mucus-secreting adenocarcinoma with metastases to the draining lymph nodes.

\section{Discussion}

This patient demonstrates a number of known associations of Turner's syndrome including duplication of the urinary collecting system (Grumbach, 1971) and diabetes mellitus (Jackson et al., 1966). It is of interest that diabetes mellitus is also a recognized association of another abnormality of sex 